PALMER, Bryan D. (...) USP - Ano IX, n. I4, p. 2I-48, 2018

\title{
Trabalho, experiência de classe e historiografia marxista : entrevista com Bryan D. Palmer
}

Bryan D. Palmer (195I) é um historiador canadense destacado por seus estudos no campo de História Social, em especial no que diz respeito à história do movimento operário e da experiência social das classes trabalhadoras ao longo do século XX. Professor da Trent University, também é reconhecido por seu engajamento político e por suas intervenções nos debates teóricos e metodológicos do marxismo. É autor, dentre outros trabalhos, dos livros "A Culture in Conflict" (1979), "Descent into Discourse" (1990), "E. P. Thompson: objections and oppositions" (1994), "Canada's I96os: the ironies of identity in a rebellious era" (2008) e "Marxism and Historical Practice” (2015).

Entrevista realizada por Maurício Orestes Parisi e Sean Purdy em 20 de novembro de 20I4, na cidade de São Paulo. Traduzida por Felipe Rodrigues Alfonso. Edição do tradutor em colaboração com a equipe editorial da RAN. 


\section{MAURICIO ORESTES PARISI \& SEAN PURDY}

Para começar, o senhor poderia nos falar sobre a origem do seu interesse por História e os primeiros anos de sua formação acadêmica?

\section{BRYAN D. PALMER}

Sempre me interessei por História. Isso é, inclusive, algo sobre o qual pensei recentemente (ao envelhecer, provavelmente se pensa mais sobre essas coisas). Quando criança, sempre me intrigava o desenvolvimento histórico. Minha primeira ideia do que fazer quando crescesse foi Arqueologia, que possui certa dimensão histórica. Cresci numa família em que esse interesse não existia. Uma educação quase filisteia. Mas, particularmente, interessava-me muito por História, que me permitiu, uma vez na escola pública, o desenvolvimento do interesse pela escrita. História e escrita, para mim, sempre estiveram conectadas. Meu interesse ficou mais sério quando, cursando o colegial na década de 1960, fui recrutado por um partido de esquerda, um grupo que esteve presente na universidade durante minha juventude em Londres (Ontário). Comecei a ler Karl Marx (I818-I883), Friedrich Engels (I820-I895), Mao Zedong (I893-1976) e interessar-me por questões relacionadas à opressão. Lembro-me de desenvolver um projeto que durou um ano sobre negros no Canadá e nos Estados Unidos.

Iniciei a minha graduação na University of Western Ontario, em Londres (Ontário), mas a cursei o mais rápido possível, sabendo que queria ir aos Estados Unidos ao final do curso. Durante o meu primeiro ano na universidade, fui sendo cada vez mais atraído pela História Social, especificamente da classe trabalhadora. Meu interesse pelo tema era ainda o de um marxismo padronizado e convencional, que concebia a classe trabalhadora enquanto agente da transformação social. Naquele momento, envolvi-me em tentativas de escrever uma história da classe trabalhadora a partir de fora (e não de dentro) da universidade. Abandonei a universidade por dois anos para me envolver no que havia restado da New Left nos anos de 1969, 1970, 1971. Foi quando li pela primeira vez E. P. Thompson (1924-1993) e os escritos de Eugene Genovese (1930-2012) sobre escravidão nos Estados Unidos. Fui a Nova Iorque para me conectar aos desenvolvimentos da esquerda no início da década de 1970. Integrei um pequeno experimento educacional chamado Alternate $U$ (Alternate University): sem notas e totalmente ministrado por esquerdistas de todos os tipos. Fiz um curso sobre a Revolução Russa, ministrado por um professor anarquista. Aprendi a argumentar, diferenciar e 
promover posições políticas de maneira vigorosa, mas camaradesca. Ali havia argumentos de todos os tipos: de diferentes setores do New Communist Movement [NCM], de maoístas, anarquistas e vários agrupamentos trotskistas. Eu acompanhava os argumentos serem desdobrados de maneira inteligente e criativa e vigorosa.

Quando retornei à universidade, trouxe para a sala de aula esse nível de argumentação e por isso não fui muito bem-recebido. Não era a maneira pela qual operava então a academia. Quando decidi me doutorar, eu não sabia ao certo o que pesquisar, pois interessava-me pela história da classe trabalhadora, pela história afro-americana e pela História Social, no sentido mais amplo. Candidatei-me a algumas universidades dos Estados Unidos e acabei indo para a State University of New York, em Binghamton. Ali trabalhava um historiador chamado Melvyn Dubofsky (1934), autor de um longo livro sobre os "Industrial Workers of the World (IWW)”. Era um historiador do trabalho de orientação socialdemocrata, simpático ao radicalismo e ao progressismo, de modo algum hostil ao marxismo. Ele, inclusive, mostrava-se aberto aos estudantes marxistas. Mas, sendo um judeu de Nova Iorque, aproximava-se mais da tradição do Labor Party nova-iorquino das décadas de 1930 e 1940. É provável que, quando jovem, ele tenha trabalhado para esses tipos de campanha. À época, o principal historiador marxista do trabalho encontrava-se em Pittsburgh: David Montgomery (1927-20II). Eu o conhecia por seus seminários de pós-graduação em Pittsburgh e Dubofsky, em Binghamton. Íamos e voltávamos uma ou duas vezes ao ano para participar de um seminário integrado, com a presença de todos. Ali pude conhecer muitos dos estudantes de Montgomery.

\section{MAURICIO ORESTES PARISI \& SEAN PURDY}

Seus contatos com organizações marxistas se davam, primordialmente, com os grupos trotskistas?

\section{BRYAN D. PALMER}

Originalmente, não. Quando jovem, na época em que trabalhava em Nova Iorque (final da década de 1960, início da década de 1970), fui atraído pelo maoísmo que, comparado ao dos dias de hoje, era muito mais influente e popular entre a esquerda. Não cheguei a integrar nenhum agrupamento, mas estive próximo a vários. Tratava-se de um verdadeiro campo cultural. Morando em Nova Iorque me envolvi com um agrupamento de maoístas, no qual realizavam-se reuniões e sessões de auto-crítica. Eles se interessavam sobretudo pela 


\section{R E V I S TA A N G E U S N O V U S}

questão nacional e por avaliar se lutas nacionais poderiam ou não ser progressistas. Tratava-se de aplicar a noção de "contradição", em Mao Zedong, para compreender se as forças burguesas no interior de um Estado colonizado possuíam um braço que fosse, ao mesmo tempo, alinhado ao imperialismo e dotado de elementos progressistas. Em Nova Iorque, a discussão girava em torno das lutas de Porto Rico, das lutas latinoamericanas, onde os maoístas possuíam grande influência. Eles tinham influência sobre os Black Panthers e sua versão porto-riquenha: os Young Lords. Num dado momento, concluí que o maoísmo era insatisfatório em termos teóricos, políticos e práticos. Decidi por abandoná-lo e considerar mais seriamente o trotskismo. Minhas influências e conexões dentro do trotskismo estavam mais concentradas nas facções de extrema-esquerda, mas mesmo assim mantive o interesse pela história social da classe trabalhadora.

\section{MAURÍCIO ORESTES PARISI \& SEAN PURDY}

Por que o senhor escolheu os Estados Unidos e não o Canadá para cursar a sua pósgraduação? Sua decisão foi impactada pelas agitações políticas e sociais do 1968 ?

\section{BRYAN D. PALMER}

O ano de 1968 impactou-me sim, mas eu ainda era muito jovem. Tinha 17 anos e morava em Londres (Ontário), uma cidade a meio-caminho entre Toronto e Detroit, relativamente isolada. 1968 reverberou entre as pessoas dali, mas, ainda assim, não havia muita agitação política. E quando se é jovem assim, dois ou três anos fazem uma diferença incrível. Os anos entre os Is e os i9 são realmente importantes em termos de capacidade política. Em I968 eu ainda estava em processo de radicalização. Para mim, 1968 seria uma influência maior posteriormente, quando retrospectivamente eu passei a interpretá-lo como algo importante.

Sobre minha ida aos Estados Unidos: em 1969 e 1970, havia somente um lugar no Canadá para se estudar a classe trabalhadora: a University of Toronto, onde estava Kenneth McKnaught (1918-1997). Mas o ano de 1968 o empurrara mais à direita, fazendo dele uma espécie de social-democrata, além de anti-marxista, anti-ativista e anti-poder estudantil. Eu não queria trabalhar com alguém assim. Não havia outro lugar onde o estudo da classe trabalhadora era encorajado e alguém fosse capaz de ensinar algo a respeito. Além disso, eu queria ter a experiência de viver nos Estados Unidos e poder realizar leituras mais amplas. Eu pensava que a história canadense poderia beneficiar-se de uma infusão das ideias, teorias e métodos que emergiam da História Social que se fazia na Inglaterra, nos Estados Unidos ou 
em qualquer outro lugar. Suponho que poderia também ter ido à Inglaterra ou a outro país, mas os Estados Unidos eram geograficamente mais próximos e representavam um choque cultural menor.

\section{MAURICIO ORESTES PARISI \& SEAN PURDY}

Qual foi o impacto (se houve algum) da Guerra do Vietnã para o movimento imigratório dos jovens de sua geração entre Estados Unidos e Canadá?

\section{BRYAN D. PALMER}

Primeiramente, o impacto se deu na "Nova Esquerda Canadense", se assim a quisermos chamar. Em termos de solidariedade com os Estados Unidos, implantaram-se mecanismos de recepção dos desertores, semelhantes aos que foram as Underground Railroads para os escravizados no século XIX. Além disso, houve a influência dos jovens em geral (e não apenas desertores), que escapavam dos Estados Unidos, e de professores de esquerda que saíam em busca de empregos no setor universitário. Na década de 1960, quando as universidades começaram a crescer (um fenômeno de massa no Canadá), elas ainda eram instituições voltadas apenas à elite. Somente partir de então as universidades tornaram-se lugares para onde os jovens da classe trabalhadoras também poderiam ir. Elas haviam crescido e, logo, necessitavam de mais professores. Não havia professores em quantidade suficiente no Canadá, então eles vinham dos Estados Unidos, e muitos deles eram radicais. Daí eu ter sido ensinado em Londres (Ontário) por um professor de sociologia fortemente influenciado por pessoas como C. Wright Mills (1916-1962) e a tradição radical norte-americana. Essa migração de norte-americanos em direção ao Canadá foi importante também para os grupos de esquerda, que viriam a ser bastante ativos ali. Obviamente, nem todos os norte-americanos que migraram eram de esquerda ou radicais. Alguns estavam, de fato, apenas escapando da guerra.

\section{MAURÍCIO ORESTES PARISI \& SEAN PURDY}

Da geração de jovens canadenses que, assim como o senhor, migraram para os Estados Unidos, pode-se dizer que emergiu um grupo mais ou menos coeso de historiadores? 


\section{R E V I S T A A N G E L S N O V U S \\ BRYAN D. PALMER}

Sim, houve um grupo de jovens historiadores canadenses, pertencentes à classe trabalhadora, que emergiu na década de 1960. Ao que me parece, esse agrupamento incluía Russell Hahn, Gregory Kealey (1948), Wayne Roberts (1944), Gene Homel e eu, além das diversas pessoas que se mantinham ao nosso redor. Éramos muito diferentes em termos de aplicação da política na realidade, mas nos unia a ânsia por escrever uma Nova História do Trabalho. Até aquele momento, a História do Trabalho mantivera um viés majoritariamente social-democrata, focando simplesmente nas grandes instituições da classe trabalhadora: sindicatos, partidos políticos e mobilizações parlamentares. Esse tipo de História do Trabalho via a tradição do CCF (Cooperative Commonwealth Federation) e do NDP (New Democratic Party) como a verdadeira política trabalhista. Estávamos mais preocupados, em termos gerais, com uma análise materialista de como as classes se formaram, lutaram e para qual direção caminhavam. Para nós, importava analisar tanto as origens materiais das classes quanto suas manifestações culturais, assim como o impacto disso tudo nas suas lutas. Esse grupo ficou conhecido no Canadá como New Labor Historians, ainda que eu ache essa expressão exagerada.

\section{MAURÍCIO ORESTES PARISI \& SEAN PURDY}

Qual era a relação desse grupo com o periódico Labor/Le Travail?

\section{BRYAN D. PALMER}

A origem do periódico se encontra nas discussões entre pessoas como Gregory Kealey e Russell Hahn, além de outros historiadores do trabalho com orientação socialdemocrata, como Irving Abella (1940). Por ser muito jovem, eu acabava não sendo próximo a nenhum deles. $\mathrm{Na}$ verdade, eu estava em Binghamton trabalhando na minha dissertação enquanto aconteciam as discussões. Entrei em contato com essas pessoas posteriormente, quando, de volta ao Canadá, escreveria sobre os trabalhadores de Hamilton entre a década de I860 e I9I4. No século XX, com a presença de Stelco e Dofasco, Hamilton se tornaria uma espécie de cidade industrial. O Labor/Le Travail, concebido como um novo periódico da história da classe trabalhadora, estava iniciando suas atividades quando retornei ao Canadá, em meados da década de I970, e logo se estabeleceria. Seu primeiro lançamento apareceu em 1976, quando as publicações ainda eram anuais. Ao final daquela década, tais publicações se 
tornaram bianuais. Não demorei muito para me envolver e, desde cedo, integrar o conselho editorial. Coube a mim o artigo principal do primeiro lançamento, intitulado "Most Uncommon Common Men” (1976), em que interpretei de maneira ampla a cultura artesã. Por volta de 1982, tornei-me editor de uma seção que criamos para resenhas de livros. Fui o editor dessa seção por Is anos e editor-geral por 17 anos. Por algum tempo, na década de I980, a história da classe trabalhadora foi muito popular no Canadá. Foi justamente nesse período que Sean Purdy iniciou os seus estudos de pós-graduação. Muitos dos meus seminários juntavam I2, talvez is pessoas, muitos dos quais jovens interessados em história do trabalho. Isso foi antes da "virada pós-moderna", que ganharia popularidade entre meados e o final da década de 1980, sobretudo após a implosão da União Soviética e as alegações de Francis Fukuyama (1952) de que a história acabara. Ellen Wood (1942-2016) escreveu sobre isso em seu livro The Retreat from Class (1986).

Sobre a noção de que o marxismo foi construído a partir de narrativas de classe ou de conflitos de classe, de que possuía um lado totalitário e de que suprimia a diversidade de experiências das múltiplas identidades, isso reverbeou no Canadá. Foi um golpe contra a esquerda e a análise de classes. Isso também impactou o campo da história do trabalho, que perdeu muitos jovens estudante de pós-graduação para estudos sobre orientação sexual, raça, etnicidade, cultura. Na medida em que o Labor/Le Travail iniciava suas atividades, no final da década de 1970 e início da década de 1980, consolidava-se na Inglaterra um debate entre cultura e estrutura: o "Richard Johnson Debate", a crítica de que Thompson seria um culturalista etc. A cultura se tornou um ponto de disputa interpretativa. Ironicamente, muitas dessas pessoas que atacavam a cultura, na década de 1980, tornar-se-iam culturalistas após a "virada pós-moderna”. Em 1989 e 1990, portanto, a História do Trabalho tornava-se menos atraente. Não que ela houvesse morrido, pois nós continuávamos a publicar. Mas, em meu papel de editor, pude presenciar que cada vez um número menor dos trabalhos enviados ao periódico tratavam de História do Trabalho no sentido mais convencional. A História do Trabalho tornou-se um campo de cruzamento, ligado aos estudos de gênero, raça e etnicidade. Isso não deixa de ser positivo, pois todos esses elementos fazem parte da história do trabalho. O problema é que ninguém mais se considerava um historiador do trabalho. Atualmente, no Canadá, são raros os jovens que diriam "sou um historiador do trabalho", mas muitas pessoas o fariam na década de 1980. Havia, inclusive, cargos sendo anunciados com a história do trabalho sendo um dos componentes importantes para a contratação, algo que não mais se vê nos dias de hoje. 
R E V I S TA A N G L U S NOVU S

\section{MAURÍCIO ORESTES PARISI \& SEAN PURDY}

Houve diálogos e correspondências entre os periódicos Labor/Le Travail e History Workshop?

\section{BRYAN D. PALMER}

Entre aqueles de nós que trabalhavam intimamente com História do Trabalho, os estudantes de pós-graduação e os jovens historiadores da década de 1980, houve quem tenha se tornado historiador do trabalho. O History Workshop foi um periódico muito influente, vigorosamente lido e discutido. Mas não houve diálogo formal entre Labor/Le Travail e History Workshop. Gregory Kealy (o fundador, em certa medida, do Labor/Le Travail) e eu fomos à Inglaterra para contatar Raphael Samuel e participar de eventos do History Workshop. Mas éramos visitantes, poucos vínculos formais foram estabelecidos. O History Workshop foi mais receptivo do que o Labor/Le Travail às discussões pós-modernas. Também discutíamos essas questões nas páginas do Labor/Le Travail. Cheguei a solicitar artigos e resenhas de pós-modernos, porque acreditava na necessidade de se promover o debate. Mas o History Workshop incorporou demais essa visão de mundo, daí não ser mais um periódico tão interessante quanto o era no início da década de i980.

\section{MAURICIO ORESTES PARISI \& SEAN PURDY}

Vou dizer o nome de algumas personalidades (entre historiadores, revolucionários e outros teóricos) e gostaria que o senhor dissese qual a influencia de cada um deles em sua formação. Para começar: León Trotsky (I879-1940).

\section{BRYAN D. PALMER}

Considero History of the Russian Revolution (1930) um trabalho clássico, tanto enquanto narrativa de um dos acontecimentos mais significativos da história mundial quanto por seu método: um método dialético que examina o desenvolvimento combinado e desigual, assim como as maneiras pelas quais o contexto estrutural enquanto conjunto de barreiras determinantes cruza-se à agência humana daqueles que ativamente interferem nos conflitos de classe. Considero a união entre agência e determinação em Trotsky incrivelmente poderosa. Fui certamente muito influenciado pela ênfase de E. P. Thompson sobre a agência humana, 
PALMER, Bryan D. (...) USP - Ano IX, n. I4, p. 2I-48, 2018

mas havia nele uma fraqueza no aspecto estrutural. Lidei com isso ao longo de toda minha carreira, em vários de meus escritos. São diferentes as sensibilidades de cada um deles. Pessoalmente, sinto-me mais inclinado a olhar para os conflitos de classe e à agência de homens e mulheres para criar a história. Tenho em mente que esses mesmos homens e mulheres nem sempre criam a história da maneira como escolhem. E que há estruturas e determinações estabelecidas por poderes externos às suas capacidades. Em meus escritos, porém, me interesso menos por tratar dessas estruturas. Não que elas sejam desimportantes, mas não é preciso necessariamente escrever em detalhes sobre elas para reconhecer sua importância.

\section{MAURICIO ORESTES PARISI \& SEAN PURDY}

Isaac Deutscher (1907-1967).

\section{BRYAN D. PALMER}

Deutscher não se tornou uma influência para mim até mais tardiamente. Mas a biografia de Trotsky, em três volumes, é magistral. Deutscher sempre tentou lidar com essa questão que envolve, novamente, agência e determinação. E também com a da organização revolucionária. Foi expulso do Polish Communist Party na década de 1930 e por isso se exilou. É uma figura poderosa e influente, tanto pela dimensão de seus escritos quanto pela tentativa de lidar com o que estava ocorrendo na União Soviética na década de 1950. Enxergava de maneira ampla os desenvolvimentos históricos. Não acho que Deutscher estava certo, por vezes julgo que ele estava errado. Ele via a possibilidade de se reformar o stalinismo na década de 1950, o que não me parece ter acontecido ou mesmo sido possível. Mas, sem dúvidas, ele estava atento a muitos dos desenvolvimentos centrais à história do século XX e às maneiras de os conceitualizar.

\section{MAURÍCIO ORESTES PARISI \& SEAN PURDY}

C. B. McPherson (1911-1987). 


\section{R E V I S TA A N G E U S N O V U S \\ BRYAN D. PALMER}

Ele foi muito influente em determinados círculos acadêmicos, particularmente na University of Toronto, onde lecionou, e mais especificamente ainda nas áreas de economia política e ciências políticas. Parece-me que ele sempre lidou com a relação entre marxismo e liberalismo. Seu primeiro livro foi sobre o Crédito Social em Alberta, um movimento direitista que teve apoio da classe trabalhadora. A análise de classe que ele realizou ali foi muito astuta. Mas o seu livro mais importante, The Political Theory of Possessive Individualism (1962), proveio um aparato conceitual a muitos dos trabalhos de Christopher Hill, que muito o admirava. Apesar de tudo, McPherson nunca se envolveu na política organizada no Canadá. É possível que ele tenha estado próximo ao Communist Party na década de 1940 e início da década de 1950. Sua mulher tinha ligações mais fortes e esteve envolvida no ativismo pacífico na época: Voice of Women e outras coisas do tipo. Acredito que ele tenha influenciado pessoas como Gad Horowitz (1936), que escreveu muito para um periódico de esquerda da década de 1960 intitulado Canadian Dimension. Mas não me recordo de ele ter sido uma influência para mim, a não ser posteriormente.

\section{MAURÍCIO ORESTES PARISI \& SEAN PURDY}

George Rudé (1910-1993).

\section{BRYAN D. PALMER}

Rudé migrou para o Canadá após ter sido forçado a sair da Inglaterra pela repressão da Guerra Fria. Ele foi primeiro para a Austrália e depois para o Canadá, tendo posteriormente lecionado na Concordia University. É evidente a sua influência em Montreal e na própria universidade, onde era reverenciado pelos estudantes. Cheguei a conhecê-lo quando lecionei em Montreal, na McGill University, entre 1979 e 1981. Ele vinha trabalhando desde muito jovem, pois a sua expulsão da Inglaterra o fez perder os direitos de pensão. Seu trabalho foi muito influente nos círculos da História Social, ainda que nunca tenha extrapolado Montreal ou o Canadá e tenha se mantido nos ambientes acadêmicos e nãopolíticos. É claro que esse era um período de pessoas muito ativas, então talvez ele tenha somente aparentado estar um pouco à margem. Acredito que os trabalhos iniciais de George tenha sido os mais influentes. The Crowd in the French Revolution (1959), The Crowd in 
PALMER, Bryan D. (...) USP - Ano IX, n. I4, p. 2I-48, 2018

History (1964), os trabalhos em parceria com Eric Hobsbaw (1917-2012), como Captain Swing (1969).

Diferentemente desses trabalhos iniciais, os seguintes foram prejudicados por seu distanciamento das fontes e dos arquivos. Isso se deveu à repressão da Guerra Fria. Quando esteve na Austrália, pesquisou sobre os exilados à Tasmânia na década de I830, e aqueles transportados do Canadá e das rebeliões de I837-I838. Trabalhou também com atividades criminais. Mas nada disso alcançou a textura profunda de sua história social pregressa, em que houve pesquisa em arquivos na Inglaterra e na França. Na minha opinião, os trabalhos tardios simplesmente não são tão bons quanto os iniciais. Foi uma trajédia ele ter sido exilado das fontes. Eu lhe dou crédito por ter continuado a trabalhar, mas havia um caráter abstrato em seus escritos que não estava presente nos trabalhos iniciais.

\section{MAURICIO ORESTES PARISI \& SEAN PURDY}

C. R. L. James (1901-1989).

\section{BRYAN D. PALMER}

James foi importante. Eu o li desde cedo (desde quando da minha transição do maoísmo ao trotskismo), particularmente o Black Jacobins (1938), um livro que ainda considero maravilhoso. James foi muito influente no grupo Facing Reality de Detroit, composto por pessoas como Marty Glaberman (1918-200I), Seymour Faber e historiadores da escravidão, como George Rawick (1929-1990). James, ainda que extremamente sofisticado enquanto marxista, acabou abandonando as noções de classe trabalhadora, partido, organização da classe trabalhadora. Ele se tornara hostil a isso, e muito crítico do leninismo ao final de sua vida.

Por volta de 1972 e 1973, lembro-me de ter ido a uma reunião do Facing Reality, em Detroit. Devo admitir que isso acabou me afastando do leninismo. Não conseguia vislumbrar essas pessoas criando quaisquer intervenções possíveis na classe trabalhadora. Eles eram incrivelmente dinâmicos, intelectuamente sofisticados, mas a conferência era um caos. Foi, de fato, um momento decisivo para a minha aproximação do trotskismo ortodoxo, em vez da versão de James do trotskismo. Apesar de tudo, James era uma figura estimulante. Seus escritos sobre dialética foram muito importantes. As histórias que ele escreveu, particularmente o Black Jacobins, são incríveis. Ou mesmo Beyond a Boundary (1963), em que ele situa o críquete no contexto do colonialismo, das relações raciais etc. 


\section{R E V I S T A A N G E L S N O V U S}

\section{MAURICIO ORESTES PARISI \& SEAN PURDY}

Retornando ao assunto dos anos 1960, como se enquadra naquele contexto a produção do seu livro Canada's Ig6os (2008)?

\section{BRYAN D. PALMER}

O livro tenta argumentar que, antes da década de 1960 (2008), havia uma mitologia do Canadá enquanto domínio de assentamento branco, enquanto posto do Império Britânico. Não resta dúvidas de que essa construção social foi aceita na experiência canadense do século XIX, e mesmo do XX, mas a realidade foi mais complicada do que isso. Imigrantes e povos nativos foram claramente retirados dessa narrativa, que se espalhava entre jornalistas, escritores e até historiadores. Um consenso brutalizante, ao mesmo tempo que brando (algo tipicamente canadense). John Diefenbaker (I895-1979), um político conservador e primeiro ministro na década de 1950 e início da década de 1960, compartilhava essa narrativa. Eles diziam “um Canadá”.

$\mathrm{Na}$ década de 1960, porém, essa narrativa foi totalmente rompida. Houve revoltas partindo de todos os tipos de pessoas. Quebec foi central, pois sempre fora uma sociedade conservadora, dominada pela Igreja e pelo catolicismo. Em 1948, houve uma greve de grande relevância em Asbestos. $\mathrm{Na}$ década de 1950 surgiram novos acontecimentos, mas foi na década de 1960 que eclodiram assentamentos nacionais radicais. Surgiu a Front de Libération $d u$ Québec (FLQ), que era mais do que uma simples organização terrorista. Ela reverberava as aspirações de muitos jovens por uma nova Quebec, o que, de fato, se realizou. A antiga Quebec foi deixada para trás, a ponto de uma sociedade até então extremamente conservadora tornar-se radical. Houve mudanças fundamentais: emergiram movimentos de mulheres, cujo impacto foi vigoroso na década de 1960 e mais ainda na década de 1970; movimentos de povos nativos e o Red Power, que se tornavam cada vez mais militantes (sempre houve protestos por parte dos povos nativos, mas na década de 1960 eles assumiram um aspecto mais militante); e movimentos estudantis, diferentes daqueles dos Estados Unidos, mas trazendo dali alguns dos mesmos aparatos, como protestos contra o imperialismo e a cumplicidade do governo canadense na Guerra do Vietnã. 
PALMER, Bryan D. (...) USP - Ano IX, n. I4, p. 2I-48, 2018

\section{MAURICIO ORESTES PARISI \& SEAN PURDY}

Acredito que a sua obra possa ser dividida em três ramos: o primeiro se preocuparia com questões teóricas; o segundo, com o campo mais geral da História Social; e o terceiro, com polêmicas e debates historiográficos. A combinação desses três ramos compóe uma obra de extrema relevância historiográfica, uma obra que tem como mérito apresentar um grande projeto.

\section{BRYAN D. PALMER}

Isso é muito gentil, obrigado! É gratificante quando as pessoas reagem dessa maneira. $\mathrm{Na}$ maioria das vezes, as reações são muito críticas. Está correta essa maneira de caracterizar minha obra. Publicarei, em breve, uma coletânea de ensaios em dois volumes pela editora Brill (Historical Materialism Book Series). O título geral é Marxism and Historical Practice (2015). No primeiro volume, cujo subtítulo é "Essays on Class Formation and Class Struggle”, estarão contidos os ensaios empíricos, embuídos de pesquisas mais aprofundadas. No segundo volume, cujo subtítulo é "Interventions and Appreciations", estarão contidos ensaios teóricos e historiográficos, além de outros, centrados em debates, controvérsias e personalidades. Há dois ensaios sobre Hobsbawm; um sobre Thompson; um sobre James P. Cannon (1890-1974); um sobre Ernest Mandel (1923-1995); um sobre Harry Braverman (19201976). Essas personalidades sempre se mostraram envolvidas com a prática política dos debates e das contestações.

\section{MAURICIO ORESTES PARISI \& SEAN PURDY}

Como o senhor o situaria o livro Descent Into Discourse (1990) em sua obra? O senhor o consideraria um ponto de inflexão em sua trajetória intelectual?

\section{BRYAN D. PALMER}

Sim, foi uma ruptura no sentido de ter um caráter explicitamente teórico e historiográfico. Em relação à minha trajetória intelectual, foi longo e demorado o processo de me considerar um marxista. No início da minha carreira, sempre relutei em fazê-lo, em parte por não pensar possuir as credenciais necessárias para isso. Respeitava demais as histórias marxistas para assumir e dizer "sou um marxista." Com o passar do tempo, porém, fui 


\section{R E V I S T A A N G E L S N O V U S}

tornando-me mais confiante e, ao mesmo tempo, mais marxista. Isso aconteceu ao longo da década de 1980, enquanto eu lecionava nos seminários de pós-graduação e atentava para o que mais interessava aos mais jovens. Era impossível não enxergar a influência do pósmodernismo, o recuo em relação à classe. Ele representava a adoção do particular em detrimento do geral, um apego às identidades diversas no lugar de considerá-las como parte de um projeto político coerente. Eu via negativamente a influência do pós-modernismo na História, justamente porque seu interesse pelo particular o fazia negligenciar a evidência, a pesquisa aprofundada em fontes primárias.

Imagina-se tomar aquela imagem [Palmer aponta para um quadro na parede] e dizer: "Vou escrever uma história inteira a respeito disso." Essa imagem interessa a todos os historiadores, digamos, da Guerra Civil Espanhola. Mas se ela mantiver o pesquisador longe dos arquivos, dos debates e das discussões, da historiografia etc.; se ela o impedir de realizar uma análise ampla, uma pesquisa aprofundada, então essa imagem torna-se uma desculpa para não se uma boa História. Percebi isso em muitos pós-modernos, particularmente estudantes. Diziam ser qualquer História tão boa quanto as demais, sendo tudo passível de interpretação. Eu estava farto daquilo tudo, mas, naquele momento, ainda não havia lido muitos dos teóricos pós-modernos. Quando decidi fazê-lo, estava me separando da minha esposa e tinha que tomar conta, pela metade do tempo, da minha filha de 4, 5 anos. Foi um momento particularmente ruim para visitar os arquivos e realizar pesquisas longe de casa, mas eu conseguia cuidar dela e, durante a noite, ler Michel Foucault (1926-1984), Jacques Derrida (1930-2004) etc.

O livro nasceu disso. Quanto mais eu lia, mais eu percebia que muito do que os pósmodernos afirmavam ser inteiramente novo já havia sido apontado por historiadores sociais. Não era como se os historiadores nunca tivessem abordado linguagem, representação e discurso. E. P. Thompson, em grande medida, trata do discurso em The Making of the English Working Class (1963), quando contrapõe os tons das escritas e dos direitos de, por exemplo, William Cobbett (1763-1835) ou Thomas Paine (I737-I809), à corrupção antiga e ao poder do século XVIII, traduzidos nas formas de governo do século XIX. Eu resolvi escrever sobre isso, tentando apontar para as maneiras pelas quais os historiadores sociais lidaram, e ainda lidam, com essas questóes. Eles poderiam se beneficiar da leitura de pós-modernos, mas o seu trabalho seria prejudicado se caíssem na armadilha do que denomino argumentos “terminalistas” (“ultimatists”). Eu queria reafimar o valor das interpretações materialistas (e, obviamente, marxistas) do desenvolvimento histórico que vinham sendo dispensadas por muitos círculos pós-modernas.

A "virada pós-modena” teve uma influência tremenda entre historiadores sociais no Canadá e nos Estados Unidos. Muitos desses historiadores odiaram Descent Into Discourse, 
tratando-o como um livro retrógrado. Mas outros não: penso aqui em pessoas como Geoff Eley (1949) e William Sewell (I909-200I) (que têm voltado a realizar interpretações materialistas e a tratar de questões de classe, ainda que não critiquem o pós-modernismo da época). Há historiadores que nunca foram partidários da pós-modernismo, como Alex Callinicos (1950), Ellen Wood, Terry Eagleton (1943) e mesmo eu.

Alguns historiadores precisaram de 20 anos para descobrir que o pós-modernismo nos afastou das análises de classe. Foi especialmente a crise de 2008 que demonstrou a importância de se abordar questões de classe e tornou impossível deixá-las de lado do debate público. Isso fica evidente pelo alarde em torno do livro de Thomas Piketty (197I), que se tornou um best-seller na Inglaterra. Ele traz Karl Marx à discussão, mas o enfraquece quando enfoca sobremaneira no aspecto da distribuição. De qualquer modo, as discussões em torno de Marx e das questões de classe retornaram. Tornou-se mais difícil ser um pós-modernismo da maneira "terminalista" ["ultimatist"] que se via na década de 1990. Ainda assim, muitos historiadores sociais no Canadá que se educaram naquele ambiente de crítica pós-moderna ao marxismo guardam uma certa hostilidade em acusações como ao "economicismo", ao “dogmatismo" etc. Não acredito, portanto, que o pós-modernismo tenha sido derrotada por completo. Vejam a quase celebridade de Slavoj Zizek (1949). Ele é alguém que falará de Marx e Lenin (I870-1924) mas que, ao mesmo tempo, foi muito influenciado pela sensibilidade pósmoderna.

\section{MAURÍCIO ORESTES PARISI \& SEAN PURDY}

Qual a opinião do senhor sobre as críticas que em geral se tem feito atualmente contra Lenin, fundamentadas numa aproximação entre leninismo e stalinismo?

\section{BRYAN D. PALMER}

A contribuição de Lenin foi imensa. Ele pegou o marxismo do século XIX (do fracasso da Comuna de Paris) e o traduziu para as realidades do século XX (do crescimento do imperialismo). Além disso, deu um tratamento mais acabado que o do marxismo de então à questão da organização política da classe trabalhadora. Foi justamente essa a contribuição que selou sua apreensão do poder revolucionário em 1917. Não é verdadeira a percepção de que Lenin era um totalitário nos mesmos moldes de Stalin, que reprimia a oposição de maneira violenta. A história da Revolução Russa mostra que havia, entre 1917 e 1921, um Estado revolucionário em relação ao qual as nações do mundo capitalista já se haviam posicionado 


\section{R E V I S TA A N G E U S N O V U S}

contrariamente, repleto de pressões internas. Mesmo grupos de esquerda, como os anarquistas, engajaram-se em atos de terror contra o Estado revolucionário. Lenin, de fato, utilizou-se do poder estatal para reprimir seus inimigos, mas ele o fez de maneira relutante e desprazerosa. Havia também um lado democrático em Lenin, como se pode ler no texto The State and Revolution (1917). Considero a investida contra Lenin um recuo que enevoa nosso julgamento, limita nossa capacidade política e, em última instância, alimenta a atmosfera antimarxista de uma Guerra Fria das décadas de 1950 e 1960. Não quero, com isso, defender que o modelo leninista seja o único capaz de realizar uma transformação revolucionária, mas somente que ele não deve ser dispensado de maneira irresponsável, como o fazem boa parte da academia e alguns setores da esquerda. Nesse sentido, os melhores trabalhos sobre isso são ainda os mais antigos, como os de E. H. Carr (I892-1982), que não era necessariamente um leninista, mas tinha uma interpretação totalizante de Lenin em seu contexto.

\section{MAURÍCIO ORESTES PARISI \& SEAN PURDY}

Em seu artigo "Reasoning Rebellion" (Labour/Le travaill, v. 50, 2002), o senhor analisa diversos historiadores marxistas britânicos, dentre eles E. P. Thompson, Eric Hobsbawm e Harvey Kaye (1949). Num dado momento, o senhor afirma que a historiografia foi precipitada ao assumir que esses historiadores conformaram uma tradição identificável, uma coletividade historiográfica. O senhor poderia reapresentar esse argumento?

\section{BRYAN D. PALMER}

Vou iniciar por Kaye. O seu livro The British Marxist Historians (1984) é uma introdução útil, mas que não se pauta em pesquisas aprofundadas do contexto que formou esses indivíduos na tradição marxista britânica. Ele os aglomera muito prontamente numa única categoria. Muitas das fontes necessárias para ele chegar à natureza dos marxistas britânicos ficaram disponíveis apenas muito tempo depois.

$\mathrm{Na}$ minha opinião, a compreensão dos historiadores marxistas britânicos deve assumir certa coerência e unidade, mas também considerar as diferenças entre eles. As diferenças entre Thompson e Hobsbawm, por exemplo, são fenomenais. Eric escreveu histórias de amplo espectro, de maneira metropolitana, grandiosa, global. E também escreveu, por vezes, histórias de grupos particulares: a coletânea de ensaios Laboring Men (1964); o artigo "Tramping Artisan"; a história do New Unionism; o debate sobre padrões de vida. Mas, no geral, realizou grandes sínteses, como The Age of Revolution (1962), The Age of Capital 
PALMER, Bryan D. (...) USP - Ano IX, n. I4, p. 2I-48, 2018

(1975), The Age of Empire (1987). Thompson, ao contrário, escrevia como um provinciano. Não no sentido paroquial do termo, mas por sempre ter se considerado um marginal, um estrangeiro. Hobsbawm, por seu lado, estava confortável no centro metropolitano. Sua formação pessoal foi a de um judeu europeu cosmopolita, atraído por e conduzido a diversos centros metropolitanos.

Não conheço o suficiente sobre Victor Kiernan (1913-2009), Christopher Hill (I9I22003) e outros para tecer comentários semelhantes, mas acredito que tenha sido central a Kiernan a sua experiência de guerra, sua permanência na Índia e a escrita a partir dessa perspectiva. John Saville (1916-2009), de certa maneira, foi igualmente influenciado por essas coisas. Thompson também, mas havia diferenças e nuances. Há um livro muito bom escrito por Wade Matthews (alguém de quem sou muito próximo) e publicado no ano passado (2014), onde se analisa a questão nacional e algumas dessas figuras. Foca-se menos nos historiadores marxistas britânicos do que nas figuras do New Left Review, mas aborda Thompson, Stuart Hall (1932-2014), Perry Anderson (1938), Tom Nairn (1932). Ele levanta questões muito interessantes e apresenta uma interpretação bem desenvolvida de Thompson enquanto escritor provinciano.

\section{MAURÍCIO ORESTES PARISI \& SEAN PURDY}

É fato que E. P. Thompson pertenceu ao grupo de escritores antes de se inserir no grupo de historiadores. Como se deu essa transição?

\section{BRYAN D. PALMER}

Isso é verdade. Mas Thompson era muito próximo a Dona Torr (I883-1957). Além disso, Dorothy Thompson esteve bastante envolvida no grupo de historiadores no New Reasoner, ainda que não tenha participado tanto do comitê editorial com John Saville e Thompson. Ela escreveu artigos e permeneceu ativa. Então é impossível não os considerar como um casal que trabalhava em conjunto, pois eles tinham um relacionamento muito forte. Politicamente, sempre caminharam na mesma direção, um influenciando o outro.

\section{MAURÍCIO ORESTES PARISI \& SEAN PURDY}

Qual foi a relação entre E. P. Thompson e o movimento/periódico New Reasoner? 


\section{REVISTA A N G L U S NOVU S \\ BRYAN D. PALMER}

A partir de 1956 e o rompimento com o Partido Comunista Britânico, Thompson passou a ter na construção de uma nova esquerda seu projeto político central. Originalmente com o The Reasoner, a ideia era convencer os membros do partido a mudar. Quando isso se mostrou impossível, o New Reasoner foi introduzido como uma tentativa de manter a chama de um novo projeto de comunismo revolucionário. Ao mesmo tempo, o Universities Eॄ Left Review circulava entre estudantes radicais mais jovens, particularmente em Oxford e Cambridge. Houve também uma discussão sobre fundir o New Reasoner com o Universities ES Left Review, algo que acabou por acontecer e a que Thompson era extremamente favorável. Outros, como Ralph Miliband (1924-1994), acreditavam que os periódicos representavam dois agrupamentos diferentes e que, portanto, a fusão não funcionaria. A fusão, por um lado, funcionou ao permitir a criação do New Left Review; por outro, não funcionou ao promover conflitos entre os membros do comitê e do conselho editoriais. Ao final, a New Left Review seria cedida a Perry Anderson.

\section{MAURICIO ORESTES PARISI \& SEAN PURDY}

Em relação aos conflitos entre E. P. Thompson e Perry Anderson, Robin Blackburn (1940) os definiu em entrevista como um "conflito entre cavalheiros". O que o senhor pensa a esse respeito?

\section{BRYAN D. PALMER}

O próprio Robin é um cavalheiro. Naquele caso, porém, houve mais do que um "conflito entre cavalheiros". Basta ler o que ambos escreveram. As figuras de Edward e Dorothy Thompson (1923-20II), no final da década de 1950 e início da década de 1960, enquanto casal do New Left Review, era carismática, influente e estimulante. Os mais jovens da Nova Esquerda que gravitavam em torno do casal foram cativados por ele, que os tratava quase como parte de sua família. Sheila Rowbotham (1943) tornou-se quase uma filha para Dorothy. Perry estava com Juliet Mitchell (1940) (autora do livro Women's Estate), sua primeira mulher. Eles eram muito próximos a Edward e Dorothy, quase como suas "crianças de serviço". Quando se iniciaram os conflitos, as "crianças” cresceram e desafiaram seus "pais". Estou sendo metafórico, mas, diferentemente de um "conflito entre cavalheiros", o que houve foi uma "revolta contra o pai". Robin nunca iria se utilizar desses termos, pois os veria como 
uma afronta a Perry. Há uma correspondência privada entre Thompson e John Saville, que somente agora se torna pública, na qual as discordâncias são acaloradas.

Em certa medida, a primeira batalha de Thompson não foi travada contra Perry Anderson, mas sim contra Stuart Hall, o primeiro editor do periódico. Essa batalha foi traumática. Quando Perry tornou-se editor, Edward (que havia dado sua bênção a favor da transição) guardava ainda grande apreço por seus trabalhos. A partir daquele momento, porém, a New Left Review seguiria uma direção inteiramente diferente, transformando-se mais num projeto de Anderson. $\mathrm{O}$ novo mote seria trazer a teoria continental à Inglaterra e educar os movimentos ingleses de trabalhadores a partir de uma interpretação teórica sofisticada do marxismo, que Anderson e Tom Nairn sentiram ter faltado ao que julgavam uma política paroquial, empirista, do "nós contra eles".

Isso não era um "conflito de cavalheiros", mas uma cisão fundamental entre duas tradições muito diferentes. $\mathrm{Na}$ interpretação de Thompson, a força do movimento inglês de trabalhadores era aquela dos (novamente) provincianos. Enquanto Anderson focava sua atenção em Lucio Colletti (I924-200I) e Galvano Della Volpe (I895-1968), Thompson o fazia em William Morris (I834-1896) e Tom McGuire. Thompson, com isso, não desprezava aquelas outras tradições, mas sim buscava não negligenciar a experiência britânica como um todo. Há um certo elitismo na acusação de Anderson de que a dimensão teórica do movimento britânico de trabalhadores era comparativamente reduzida. Não acredito que seja esse o caso quando se atenta, por exemplo, para o movimento francês ou os movimentos da Europa Ocidental.

\section{MAURICIO ORESTES PARISI \& SEAN PURDY}

Como o senhor enxerga a influência de Antonio Gramsci (I89I-1937) e de Vladimir Lenin para esses historiadores?

\section{BRYAN D. PALMER}

Hobsbawm sempre escreveu sobre Gramsci. Lembro-me de um longo artigo dele a esse respeito, publicado por volta de 1973 no The New York Review of Books. Thompson teve algum contato com Gramsci na década de 1970, em meio ao processo de escrita do The Poverty of Theory (1978). É possível, inclusive, que ele tenha referenciado Gramsci num debate com Perry Anderson, na década de 1960. Mas me parece que Perry leu Gramsci mais seriamente do que Edward à época. Em relação ao que retiveram do leninismo, acredito que 


\section{R E VISTA A N G E L U N O V U S}

Christopher Hill tenha retido muito mais, visto que o seu leninismo foi sempre mais forte. Ele escreveu um pequeno livro sobre Lenin e a Revolução Russa em 1940. Hobsbawm nunca escreveu muito a esse respeito, mas suponho que ele também tenha retido algo do leninismo. Thompson não se mostrou atraído por Lenin depois 1956.

\section{MAURÍCIO ORESTES PARISI \& SEAN PURDY}

Como o senhor interpreta a relação da New Left Review com o Terceiro Mundo?

\section{BRYAN D. PALMER}

E. P. Thompson nunca se isolou dos acontecimentos do Terceiro Mundo. Há no New Reasoner artigos sobre Mau Mau e Quênia, artigos de antropólogos como Peter Worsley (1924-2013), que escreveu sobre o “culto à carga” na Melanésia. Foram estabelecidos contatos com dissidentes da Europa Oriental e de Cuba (C. Wright Mills, sob a aprovação de Fidel Castro, chegou a tentar levar Edward e Dorothy Thompson a Cuba). Por volta de 1962 ou 1963, Thompson escreveu uma carta de renúncia de 30 páginas reconhecendo o bom trabalho realizado pela New Left Review em relação ao Terceiro Mundo. Os escritos de Perry Anderson sobre a Angola, por exemplo, haviam sido excelentes. Mas Thompson atentava para um artigo em particular, publicado nos primórdios do New Left Review, que acusava as classes trabalhadoras do mundo capitalista avançado de estarem inteiramente comprometidas e defendia que o potencial revolucionário migrara para o Terceiro Mundo. $\mathrm{Na}$ visão de Thompson, era preciso evitar esse tipo de “terceiro-mundismo" e, simultaneamente, desenvolver interpretações perspicazes e conscientes do papel do imperialismo. Após a saída de Thompson, Anderson consolidou um conselho editorial alinhado com o Terceiro Mundo e a estratégia bélica maoísta. Foi o período maoísta vermelho deles, em que a New Left Books chegou a publicar manuais vietnamitas sobre guerra global. Seguiu-se a esse um breve período trotskista, após o qual, na década de 1970, emergeria a teoria continental. Foi quando Louis Althusser tornou-se um grande nome.

\section{MAURÍCIO ORESTES PARISI \& SEAN PURDY}

O que o senhor pensa sobre a obra de Louis Althusser (1918-1990) e sobre a crítica de E. P. Thompson a ela? 


\section{BRYAN D. PALMER}

É uma obra difícil de se ler, escrita numa linguagem muito particular ao estruturalismo e à filosofia, mas com trabalhos de grande mérito, como Ideology and Ideological State Apparatuses (1970). Acredito que a crítica de Thompson em The Poverty of Theory, ainda que fascinante, tenha sido excessiva. Não o considero seu melhor trabalho. Ele o escreveu bravo e de maneira "arrastada". Por outro lado, esse tipo de althusserianismo foi muito influente em alguns dos historiadores sociais da década de 1970. Vejo, inclusive, paralelos com o pós-modernismo. Gareth Stedman Jones (1942), por exemplo, foi muito influenciado por Althusser, mas partiu do althusserianismo (em Outcast London, 1971), passou pelo pós-modernismo (em Languages of Class, 1983) e chegou ao final da década de I980 e início da década de 1990 considerando o marxismo irrelevante.

\section{MAURÍCIO ORESTES PARISI \& SEAN PURDY}

A obra de E. P. Thompson foi inicialmente apropriada por estudiosos brasileiros, a partir dos anos 1980, a partir de um viés culturalista e não marxista...

\section{BRYAN D. PALMER}

O que há de mais interessante em Thompson é sua recusa criativa em ser enquadrado no interior de paradigmas intelectuais e políticos. Ele produziu histórias incrivelmente criativas, particularmente em The Making of the English Working Class. Esse livro teve uma influência global inegável, criando uma nova sensibilidade, uma nova visão de mundo a respeito da experiência de classe. Mas ele também abriu uma "caixa de Pandora" para o que viria a ser o pós-modernismo. Ele mesmo não tinha simpatia pelo pósmodernismo, mas a sua definição de classe enquanto agência e subjetividade abriram caminho para que esses dois termos fossem interpretados de maneiras extremas. É compreensível que se aplique às ideias de Thompson com ênfase no aspecto cultural ou mesmo, de maneira crítica, à primazia do aspecto material. O problema é que o próprio Thompson teria rejeitado essas aplicações.

O contexto da década de 1980 não era o mesmo no qual foi escrito The Making of the English Working Class. Mas, mesmo no período pós-The Poverty of Theory, quando Thompson afastou-se do marxismo, ele nunca prescindiu de interpretações materialistas. Ele nunca transformou os seus trabalhos em ataques ao marxismo, o que era típico do período de 


\section{R E VISTA A N G E L U N O V U S}

Guerra Fria. Ele sempre acreditou que o marxismo trazia vários tipos de questões importantes e, por isso, sempre se considerou um materialista histórico. Da década de 1940 até sua morte, Thompson foi formado por e esteve engajado com o marxismo, ainda que nos últimos anos de sua vida o marxismo já não construísse tanto mais seus estudos históricos e sua atuação política. Mas ele nunca foi um apóstata. $\mathrm{Na}$ verdade, ele escreveu contra apóstatas em seus trabalhos, vivessem eles na década de 1790, como William Wordsworth (I770-1850) e os românticos, na década de 1930, como Karl Kautsky (1854-1938), ou em outras épocas.

\section{MAURÍCIO ORESTES PARISI \& SEAN PURDY}

Retornando à sua obra, o que levou o senhor a escrever o livro James P. Cannon and the Origins of the American Revolutionary Left (2010)?

\section{BRYAN D. PALMER}

Eu pensava em escrever sobre Cannon já na época que gravitava em torno de Trotsky. Tanto ele quanto Maurice Spector (I898-1968), ambos envolvidos na fundação do movimento trotskista norte-americano, nunca haviam sido historiados. Me surpreende que em minha geração tantos historiadores do trabalho ligados ao New Left Review tenham pesquisado o Partido Comunista (ainda que o periódico fosse essencialmente formado como dissidência da atuação política da velha esquerda), mas nunca Cannon. Os únicos escritos sobre Cannon saíram do Socialist Workers Party, mas esse interesse não existe mais entre os quadros do partido. Foi um sujeito histórico fascinante. À época, o Partido Socialista era composto por John Reed (1887-1920), Louis Fraina (I892-1953) e pela formação do movimento comunista clandestino. Cannon ocupou o cargo de primeiro presidente do Partido Comunista, mas foi posteriormente expulso do partido e apagado de suas histórias, assim como Trotksy foi apagado das imagens da Revolução Russa. Envolveu-se em lutas importantes ao longo da década de 1930, inclusive na greve dos Teamsters, sendo eventualmente preso junto a Max Shachtman (1904-1972). Mas exerceu um papel fundamental também nos bastidores, tornando-se editor e colunista do jornal The Organizer e aconselhando muito bem os líderes da greve (os irmãos Dunne, Farrell Dobbs e Carl Skoglund). Essa liderança era excelente mas, por vezes, hesitante. Confiava-se demais no governador do Farmer-Labor Party Floyd Olson (I89I-1936) e aceitava-se a arbitragem como uma medida aceitável para a resolução desse tipo de conflito. Em seu papel de líder do partido, Cannon foi muito ativo no American Committee for the Defense of Leon Trotksy, reunido no 
PALMER, Bryan D. (...) USP - Ano IX, n. I4, p. 2I-48, 2018

México, no qual também John Dewey (1859-1952) esteve envolvido. Na década de 1940, acabou sendo preso. A atuação de Cannon e do Socialist Workers Party no seu julgamento é um exemplo de como se realizar uma defesa trabalhista em resposta à repressão estatal. Podese oferecer manobras legalistas ou, como o fizeram, uma defesa política. Ele permaneceu um comunista revolucionário até sua morte, em 1973. Há muitas lições que os jovens militantes de hoje podem aprender com a vida de Cannon. Não escrevi esse livro com o intuito de vender milhares de cópias, mas de contribuir com algo a que os jovens possam recorrer caso as coisas mudem no futuro.

\section{MAURICIO ORESTES PARISI \& SEAN PURDY}

Por que o senhor decidiu destacar, no livro Revolutionary Teamsters (2013), a greve dos caminhoneiros de 1934 ?

\section{BRYAN D. PALMER}

O Revolutionary Teamsters foi concebido no interior das lutas dos dias de hoje. No processo de escrita do segundo volume do livro de Cannon, acabei escrevendo um longo capítulo sobre a greve dos Teamsters. Foi quando eclodiram os movimentos Occupy, cujo tom geral era o de que sindicatos seriam grandes negócios, instituições burocráticas em relação às quais se deveria manter distância. Obviamente, houve movimentos mais próximos aos sindicatos. Na área de baía de Oakland (São Francisco), por exemplo, onde os movimentos estiveram vinculados ao sindicato de estivadores (composto por esquerdistas revolucionários e dotado de uma longa tradição de militância), houve a tentativa de uma greve geral vinculada aos sindicatos. A minha vontade de mostrar aos demais movimentos sociais o que pode ser um sindicato me fez transformar o capítulo em livro. É preciso saber que o sindicato pode ser transformado, mas que para isso é necessário lideranças, um senso prolongado de desenvolvimento, a vontade de se engajar nos conflitos de classe e a atitude de levar as massas de trabalhadores à militância. Na Mineápolis de 1934, a situação para trabalhadores e sindicatos era tão complicada quanto hoje em dia, mas eles as superaram. 
R E V I S T A A G E L U N O V U S

\section{MAURÍCIO ORESTES PARISI \& SEAN PURDY}

Ainda a respeito da formação histórica da classe trabalhadora, o senhor poderia comentar a sua crítica ao livro de Peter Linebaugh (1943) e Marcus Rediker (195I), The ManyHeaded Hydra (2000)?

\section{BRYAN D. PALMER}

Peter e Marcus são meus amigos. Todos os livros que escreveram são incrivelmente estimulantes e balanceados. Espero que minha resenha tenha transmitido a seguinte ideia: tenho uma sensação positiva em relação ao livro, mas nosso ofício nos obriga também a um rigoroso engajamento crítico. Há um certo romantismo na interpretação deles, resultante de estarem alinhados à tradição da "história vista de baixo". Esse é um termo problemático, pois não pode haver uma história vista de baixo, mas somente uma história que trate de maneira séria e rigorosa as lutas dos oprimidos e explorados. Essas, porém, estarão sempre enquadradas pelo que está acontecendo "acima”: pelas agendas, estruturas e contextos determinados pelo capital e pelo poder. Eu falava anteriormente sobre "evidência".

É justamente nessa direção que vai minha crítica ao The Many-Headed Hydra. Peter e Marcus querem se utilizar de uma lógica de solidariedade de classes que deveria ter existido, um laço entre escravizados, tripulantes e Jack Tars. Concordo ter havido um laço entre classes e, no melhor dos casos, uma unidade. Mas eles quiseram se utilizar desse anseio e transformálo em realidade histórica, afirmar a existência de uma aliança. Segundo minhas pesquisas (lembrando que não sou especialista na área), há poucas evidências para sugerir que, de fato, forjaram-se alianças. Isso não surpreende, dadas as determinações que situavam brancos e negros em diferentes níveis. Havia diferenças significativas entre a opressão encarcerante da escravidão e a vida da classe trabalhadora marítima. Além disso, tratei da análise que eles realizaram dos irlandeses em determinados contextos caribenhos. Se eu não estivesse consciente dessas evidências e de outros escritos que sugerem algo diametralmente oposto ao que defendem Peter e Marcus, eu estaria mais aberto ao argumento.

A visão política de Peter é definida por um certo anarco-marxismo (evidenciado por seu envolvimento no grupo Zerowork). Ele foi muito influenciado por interpretações “espontaneístas” do conflito de classes, bastante diversas daquelas de E. P. Thompson em The Making of the English Working Class. Não há dúvidas de que Peter e Marcus realizaram pesquisas documentais aprofundadas, que o livro é extremamente importante e influente, que dá um bom direcionamento a debates conceituais. Minha discordância reside somente na 
afirmação de que esses conflitos de classe "vistas de baixo" são tão potentes e poderosas quanto sugerem os autores.

\section{MAURICIO ORESTES PARISI \& SEAN PURDY}

No artigo Reconsiderations of Class (2014), o senhor discute a categoria "precariado". Quais as suas considerações sobre ela?

\section{BRYAN D. PALMER}

É um artigo para o periódico Socialist Register. As origens desse trabalho são interessantes, pois diferentemente de Ruy Braga (1972) eu nunca estudei a fundo o precariado. Atualmente, tenho trabalhado em parceria com Gaetan Heroux num livro sobre o ativismo anti-pobreza em Toronto. Trata-se de um estudo a respeito dos mais despossuídos em Toronto, da década de 1830 até os dias de hoje. Analisamos a maneira pela qual as instituições estatais criminalizam e marginalizam os pobres e como as periódicas crises do capitalismo intensificam essa dispossessão. Eu havia já escrito um artigo a esse respeito, que acabou sendo publicado no Labor/Le Travail, sobre o período inicial (grande parte do século XIX e início do século XX), em que resgato a discussão de Karl Marx sobre os despossuídos.

Os historiadores do trabalho escreveram sobre os empregados, mas é preciso atentar igualmente para os desempregados, casualmente empregados e trabalhadores forçados, pois eles também compóem aquele capitalismo que Marx acabou por odiar, de pauperismo, despossessão e miséria.

Eu não havia lido o livro de Guy Standing (1948) sobre o precariado, mas os editores do Socialist Register, tendo lido meu artigo no Labor/Le Travail, sugeriram que eu escrevesse algo sobre ele para ser publicado num volume que estava sendo preparado sobre classe. Naquele momento, eu nem ao menos sabia quem era Guy Standing. Eu o li e concluí haver em sua obra resíduos do pós-modernismo. Os pós-modernos tendiam a privilegiar questões como performatividade, representação e discursividade em detrimento de política. Mas Standing aborda a organização política. Ele defende que o precariado necessita organizar-se enquanto classe separada, carregar suas próprias bandeiras, ocupar a arena pública e garantir seus direitos. Não vejo problema na organização do precariado, mas é preciso fazê-lo conectando-se a outras organizações de classe, de maneira a criar a possibilidade de uma mobilização coerente mais ampla que unifique todos os trabalhadores, sejam eles assalariados 


\section{R E V I S TA A N G E U S N O V U S}

ou não, brancos ou negros, homens ou mulheres. Assim é o capitalismo: "Tudo o que é sólido desmancha no ar”.

Mas o processo continua. $O$ processo da acumulação primitiva continua a se reproduzir. Então, sim, o trabalho é precarizado nos dias de hoje. E sim, há um número crescente de trabalhadores precarizados, inseguros e não-representados por sindicatos. Mas isso, na história geral do capitalismo e da formação de classes, não há novidades. Proletarização sempre foi sinônimo de precarização. O projeto da organização marxista é justamente unir pessoas diferentes em torno de uma questão comum: o fato de serem a massa de pessoas da sociedade mas terem seus destinos controlados por um grupo minúsculo de indivíduos. O projeto político marxista sempre foi o de reverter esse quadro. Isso será feito pelas lutas dos sindicatos, mas não somente. Pelas lutas dos pobres e dispossuídos, mas não somente. Será preciso que eles se unam a outros agrupamentos em torno de, novamente, uma questão comum: o fato de terem sido alienados de seu poder de autoridade, de terem sido dispossuídos da propriedade e do controle não apenas da produção, mas (nos dias de hoje) da distribuição, dos serviços etc. Precisamos criar um Estado que verdadeiramente represente a massa de pessoas.

\section{MAURICIO ORESTES PARISI \& SEAN PURDY}

Para terminar, duas questões relacionadas à atualidade. Em primeiro lugar: como o senhor interpreta os protestos que têm recentemente tomado o mundo e, em particular, as assim chamadas "Jornadas de Junho de 20I3" no Brasil?

\section{BRYAN D. PALMER}

$\mathrm{Na}$ América do Norte, tivemos insurreições com características semelhantes às das "Jornadas de Junho de 2013" (ainda que menores), como os movimentos Occupy nos Estados Unidos e os protestos contra o G-20 e o G-8 no Canadá. Neles, há grupos como os Black Blocks, que se dizem anarquistas (muito embora sua compreensão do que seja o anarquismo não me pareça muito desenvolvida) e são anti-leninistas. Eles estão se levantando, militando e dispostos a lutar, mas é frustrante ter que constantemente repassar questões de estratégia e de organização políticas. Quando falo com esse tipo de pessoa, reforço a necessidade de se reunir a energia e a capacidade de resistência e de interação via mídias sociais que têm esses grupos para construir do zero mobilizações imensas, mas de o fazer a partir de noções da esquerda 
antiga de organização partidária, aparato disciplinado, continuidade e luta. É frustrante ter que falar dessa maneira, mas essa é a natureza da política.

Gerações, contextos e lutas atravessam mudanças, de modo que os jovens, sangue dessas lutas, inevitavelmente percebem seu projeto como diferente dos antigos. Num dado momento, experiência e entusiasmo acabam por se fundir, mas atualmente a esquerda revolucionária é diminuta. No Canadá e nos Estados Unidos ela foi dizimada. Não há mais organizações e pouco dela se vê nas grandes manifestações. Um partido como o PT, essencialmente desejoso de se manter no poder, buscará quebrar esses movimentos para enfraquecer sua força de oposição e posteriormente integrá-los ao Estado por meio de concessões. Mas muitas das pessoas que saíram às ruas nas "Jornadas de Junho de 2013" resistiram a esse clientelismo. Essa é a característica de movimentos como esse: haverá setores da liderança interessados nesse tipo de relação com o Estado, mas também pessoas (e aí reside o potencial desses movimentos) cuja sensibilidade política as farão resistir a esse clientelismo. Para elas, o Estado é um inimigo. Deve-se superar, porém, a visão de que todo tipo de Estado e de organização partidária são inimigos. Uma esquerda grande, que consiga relacionar-se a esses grupos, funcionar de maneiras não-sectárias e criar caminhos comuns estará mais próxima de tanto consolidar a esquerda revolucionária quanto criar novas possibilidades de atuação.

\section{MAURÍCIO ORESTES PARISI \& SEAN PURDY}

Qual a visão do senhor sobre o futuro do marxismo e da esquerda revolucionária?

\section{BRYAN D. PALMER}

Gosto muito de um livro de Perry Anderson intitulado Considerations of Western Marxism (1976), em que ele argumenta que esses debates podem se resolver ou se intensificar em resposta ao renascimento dos conflitos e insurgências populares. $\mathrm{O}$ marxismo e sua vivacidade sempre guardaram relação com o ritmo e a natureza dos conflitos de classe. Quando eles recuam, o marxismo segue por caminhos teóricos selvagens e errôneos. A trajetória material da ordem global (e vivemos cada vez mais numa ordem global) confirma algumas verdades da tradição marxista: a importância fundamental da esfera material, a desigualdade social e exploração, o desenvolvimento regional e o desenvolvimento desigual, o subdesenvolvimento. Essas grandes questões globais podem ainda ser abordadas analiticamente a partir de um enquadramento marxista. Temos sempre que lidar com a classe: 


\section{R E V I S TA A N G E U S N O V U S}

o que é, como é formada, quais são seus principais elementos. A noção de conflito de classe, de luta dos dispossuídos para transformar a sociedade, é a única esperança contra um futuro atolado num capitalismo inerentemente impulsionado por crises e contra o impacto destrutivo disso nas pessoas do mundo. Incluem-se, agora, os impactos ambientais, que a ciência não mais permite serem negados.

A esquerda revolucionária marxista está, ao menos no mundo capitalista avançado, no patamar mais baixo desde seu surgimento no século XIX. Ao mesmo tempo, o imperativo do movimento marxista nunca foi tão necessário. A questão é se poderá o marxismo traduzir a riqueza e a verdade de sua análise. Se poderá o marxismo transmitir realidades terrivelmente necessárias, quais sejam as da transformação social, da derrubada do capitalismo e da criação de novos tipos de sociedades para as massas de pessoas, desejosas de utilizarem seu poder (que é considerável) para a construção de movimentos que, de fato, transformem o cenário global.

Me sinto desapontado e muitas vezes desesperado frente às realidades do momento presente, mas acredito que elas acabarão tomando rumos positivos. Ainda defendo ser o marxismo, enquanto análise e projeto político, a única esperança. E é justamente por ser a única esperança que ele prevalecerá. A frase “socialismo ou barbárie” esteve presente desde o início da década de 1960, mas ela nunca foi mais verdadeira do que agora. 